\title{
Empirical comparisons of malpractice claims of different medical specialties
}

James Reich* and Alan Schatzberg

*Correspondence: james.reich@ucsf.edu

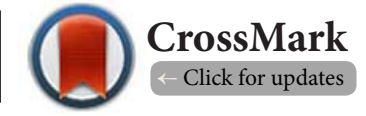

Department of Psychiatry and Behavioral Sciences, Stanford University Medical School, Stanford, California, USA.

\begin{abstract}
Background: Variables affecting malpractice rates are important to the medical profession. Empirical data on trends in malpractice payments and settlements from anesthesiologists, surgeons, pediatricians and psychiatrists over an eight-year period are publicly available for analysis.

Methods: A literature search of PubMed and Index Medicus was conducted for the years from 1985 to 2013 using the search terms National Practitioner Data Bank, physicians, and malpractice. Data from the National Practitioner Data Bank (NPDB) calculated proxy variables for the different specialties for the years 2004 to 2011 for frequency of malpractice settlements and mean settlement per incident.

$\underline{\text { Results: }}$ The literature review revealed both systemic and individual factors related to the incidence of malpractice lawsuits and settlements. Systemic factors included the "fault" system of malpractice and high and low risk specialties. A recurring theme of individual factors was failure to make the correct diagnosis. The NPDB rates of malpractice and payments over the study period declined for all specialties. The trend in improvements differed somewhat by specialty.

Conclusions: Although individual factors might be amenable to improvement by the individual physician, systemic factors are beyond the control of the individual practitioner and would need to be managed on a public policy basis.
\end{abstract}

Keywords: Malpractice, national practitioner data bank, physicians, diagnostic errors

\section{Introduction}

Malpractice has been an important issue for physicians and society at large. One estimate of the cost of medical liability found that overall annual medical liability system costs, including defensive medicine, totaled $\$ 55.6$ billion in 2008 dollars, or 2.4 percent of total health care spending [1]. These findings apply to the United States and may not be applicable to other countries.

Time and stress costs to physicians have been shown to possibly affect the delivery and quality of medical care. Martin et al., [2] performed a questionnaire study of physicians who were sued for malpractice. They found that malpractice suits created a great amount of stress that could reduce over time, but not back to baseline level. Seabury et al., [3] estimated the amount of time a physician spends dealing with malpractice in the course of a regular practice. They found that the average physician spends 50.7 months-almost 11 percent-of an assumed forty-year career with an unresolved, open malpractice claim.
They noted that although damages are a significant issue in how doctors perceive medical malpractice, perhaps more distressing to the doctor and the patient may be the amount of time it takes these claims to be adjudicated.

Because of the importance of this issue, we decided to do a review of the empirical literature on individual and systemic factors that affect the frequency of malpractice. We also utilized an empirical database, the National Practitioner Data Bank (NPDB), to examine trends in malpractice over an eight-year period.

\section{Methods and results \\ Literature search}

A literature search was conducted using PubMed and Index Medicus for the years 1985 through 2013. The search termsNational Practitioner Data Bank, physicians, and malpracticewere used both individually and in combination to survey the broadest spectrum of the literature. Articles that used empirical 
Reich et al. Journal of Public Health Aspects 2015,

http://www.hoajonline.com/journals/pdf/2055-7205-2-2.pdf

doi: $10.7243 / 2055-7205-2-2$

data to address the issue of malpractice were selected.

\section{Systemic factors}

\section{Reducing physician errors}

After examining the issue of reducing physician errors without punitive measures, Amaral-Garcia and Grembi [4] reported on an interesting natural experiment conducted in Italy. From 2001 to 2008 , some districts decided to monitor medical liability expenditures, while other regions did not. Even though there was no financial penalty to the physicians being monitored, the expenditures in those areas with physician monitoring revealed $15 \%$ less in malpractice costs. This appeared to indicate there were non-punitive ways in which to reduce malpractice.

Another non-punitive approach to reducing malpractice payments was reported by Brooks et al. [5]. Under examination was the use of Physician Health Programs (PHPs), peerassistance organizations that provide support to physicians struggling with addiction, or with physical or other mental health challenges. After monitoring, those enrolled in the program showed a $20 \%$ lower malpractice risk than a matched cohort. Furthermore, physicians' annual rates of claims were significantly lower after participation in the program $(P<0.01)$.

\section{Malpractice rates}

Chandra et al., [6] found that premiums charged by malpractice insurers may be influenced by factors that have nothing to do with quality of care. Chandra points out that decline in insurers' investment income may be influenced by such non-medical factors as interest rates. Therefore, premiums could reflect changes in investment income, not just changes in malpractice payouts. Zuckerman et al., [7] found a similar result to that of Chandra. Danson [8] found the only malpractice legislative changes that affected the amount of malpractice payouts were in states that enacted shorter statutes of limitations or payment caps.

\section{Electronic health records}

Victoroff et al., [9] examined the issue of electronic health records in Colorado physicians. It was hypothesized that the use of electronic health records would reduce malpractice events. However, physicians who did and did not use electronic health records had a similar rate of malpractice claims.

\section{Financial pressures on physicians}

There are two reports on the effect of financial pressures on physicians. An abstract by Ragan and George [10] indicates that the increase level of debt in dentists may lead to overtreatment, practicing beyond their level of expertise, performing procedures for which they have little or no formal training, reducing referrals to specialist dentists, and focusing their marketing and practice to make it more lucrative. Lee et al., [11] found that financial pressures in radiologists resulting in increased workload can lead to increased physician errors.

\section{High risk specialties}

There appear to be some specialties that are at greater risk of being sued than others. Jena et al., [12] noted that the high-risk specialties include those that involve some form of surgery (neurosurgery, cardiac surgery, general surgery, orthopedic surgery, and plastic surgery). At the bottom of the list are psychiatry, pediatrics, "other specialties", and family general practice. The remaining specialties fall somewhere in between.

Caroll and Buddenbaum [13] found a slightly different group of high- and low-risk specialties: High liability specialties were emergency medicine, general surgery, obstetrics, and radiology while low liability specialties were general and family practice, internal medicine and pediatrics. Thirty-three percent of claims resulted in indemnity payments in high-liability risk specialties compared to $28 \%$ for low-liability risk specialties $(p<0.001)$. Although the differences are significant, they indicate that high and low risk specialties carry considerable risk. Furthermore, Caroll and Buddenbaum [13] found variability in payment claims within high and low risk specialties, not just between them. They felt that differences in the reasons for which claims are initiated for high- and low-liability risk specialties likely necessitate different risk management solutions.

Although relevant in terms of relative risk, the distinction between high- and low-risk specialties to some extent obscures the tendency of all doctors to be sued. Jena et al., [12] estimated that by the age of 65 years, $75 \%$ of physicians in low risk specialties had faced a malpractice claim as compared with $99 \%$ of physicians in high-risk specialties. This does not preclude the possibility that high- and low-risk specialties might require different risk management approaches.

\section{Individual factors involved in malpractice Failure to make a correct diagnosis}

Among the empirical reports on malpractice, one theme appears in many reports: The failure to make a correct diagnosis. In a report using the NPDB, Chandra et al., [6] found that for the years 2001 to 2003, the largest issues of malpractice payments involved diagnosis, surgery, and treatment. Bishop et al., [14] used the NPDB to compare inpatient and outpatient malpractice variables for years 2005 to 2009. They found that the most common issue for malpractice in the inpatient setting was surgery whereas in the outpatient setting it was diagnostic issues.

Tehrani et al., [15] examined NPDB data in aggregate (not by specialty). They analyzed malpractice claims for years 1986 to 2010 . Diagnostic errors were the leading issue (28.6\%) and accounted for the highest proportion of total payments (35.2\%). Diagnostic errors more often resulted in death than other allegation groups $(40.9 \%$ vs. $23.9 \%, p<0.001)$ and were the leading cause of claims-associated death and disability. More diagnostic error claims were outpatient than inpatient $(68.8 \%$ vs. $31.2 \%, p<0.001)$, but inpatient diagnostic errors were more likely to be lethal $(48.4 \%$ vs. $36.9 \%, p<0.001)$.

Wallis [16] performed a literature review on empirical studies 
that indicated risk factors for malpractice in primary care. The most common risk factor was missed or delayed diagnosis with a range in the studies between 26 to $63 \%$ of all claims.

\section{Do previous malpractice claims indicate a higher risk for the future?}

There is also the issue of whether those physicians who have had previous malpractice claims are more liable to incur additional claims in the future. Sloan et al., [17] examined a Florida malpractice database and concluded that most insurer payments were accounted for by a relatively small number of doctors and that those doctors were likely to have more complaints filed against them in the future. This would seem to indicate an at-risk group of doctors.

Entman et al., [18] came to a different conclusion after examining malpractice in Florida obstetricians. No relationship was found between prior malpractice claims experience and the technical quality of practice for this group. Entman et al., [18] felt that strategies that attempt to identify physicians at risk for future clinical errors by using data on prior malpractice claims (such as the National Practitioner Data Bank) might be misjudging the likelihood that substandard clinical care will be provided by physicians with prior claims.

Taragan et al., [19] came to a conclusion in between the two studies cited above. They found that most physicians with high malpractice rates tend to improve over time; however, they did find that consistently high rates might indicate a more refractory group. As Taragan's findings are between the results of the other two reports, this may be a reasonable conclusion for the empirical data we have at this time (Table 1).

Table 1. Systemic and individual factors that may contribute to malpractice rates.

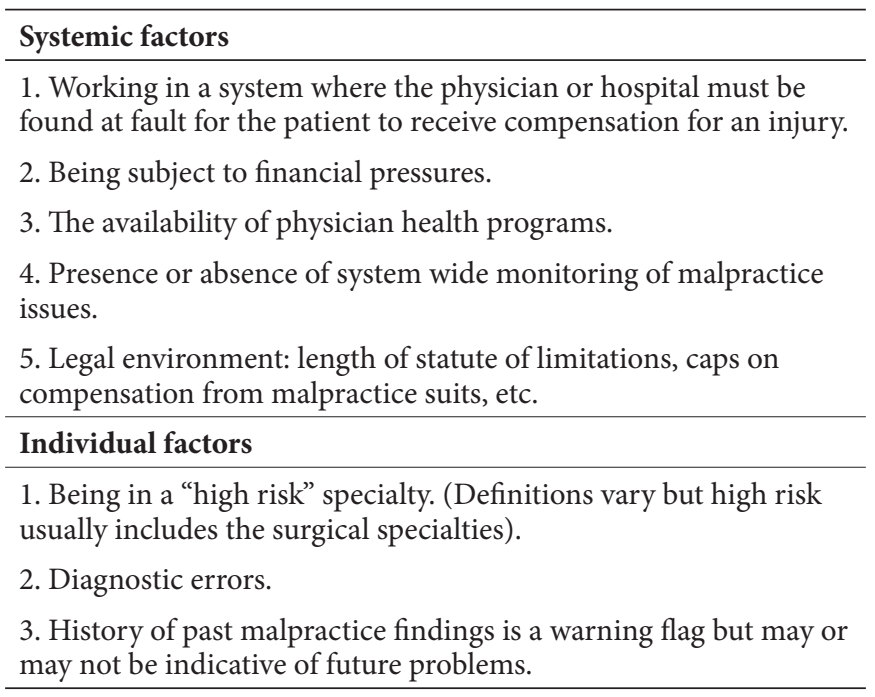

Data analysis

Data from the National Practitioner Data Base (NPDB) was analyzed. The NPDB is a publicly available database $[\mathbf{2 0 , 2 1 ]}$.
By law, physician malpractice lawsuits and settlements are required to be reported to the NPDB.

The NPDB was designed not as a research database but as a central clearing house for reporting medical malpractice judgments against physicians and other health professionals. By having one central place to report, it became easier to track problems of individual physicians. It provides a reliable way for hospitals or potential employers to verify whether there have been difficulties resulting in legal judgments against a physician. Information reported includes malpractice judgments, amount of payment, and discipline taken by a medical society or hospital.

Information from the National Practitioner website [21] was accessed online. Estimates of the data for anesthesiologists and pediatricians used methods previously published on this issue $[\mathbf{2 2}, \mathbf{2 3}]$. Estimates of psychiatrist data were performed by separating out those incidents indicated to be of a mental health nature (ALGNNATR=100) and where the credential of the practitioner was doctor of medicine (licnfeld). Estimates of surgeons were based on surgery related incidents (ALGNNATR=20). The starting year was 2004 because this was the first year a behavioral health variable that allowed an estimate of psychiatric malpractice was utilized and the years 2004 until 2011 were examined.

Calculations for dollar amount of malpractice claims used the variable total payment divided by the number of incidents. These dollar amounts were all adjusted to 2004 data using the Bureau of Labor Statistics database to estimate inflation. Each payment was multiplied by the factor CPI2004/CPIx where CPIx is the Consumer Price Index for Year X. Payments over years were analyzed using a linear model with effects of year, specialty group and year by specialty group interaction. Year was treated as a continuous, linear predictor. Trends within specialties, and comparisons of trends between specialties, were then estimated using this model. We examined the dollar amount calculation, as it would be a proxy for the seriousness of the malpractice incidents.

Calculations of incidence were completed by calculating the total number of malpractice incidents for each specialty and adjusting the rate per 100,000 population for that year. Specifically, the claim rate is $100,000 \times$ Number of Claims for Year X/US Population for Year X. Population estimates were taken from the United States Census database. Rates were analyzed using the same linear model as for payments. Again, trends for each specialty were estimated by the combination of coefficients from the main effect of year and the appropriate portion of the specialty by year interaction. Differences of trend estimates were also computed to test specialty differences in trends over time. Computations were calculated using SAS Version 9.3 (SAS Institute, Cary, NC).

\section{Data analysis results}

Table 2 and Figure 1 give the rates of claims for malpractice reported to the NPDB per 100,000 of the United States pop- 
Reich et al. Journal of Public Health Aspects 2015,

http://www.hoajonline.com/journals/pdf/2055-7205-2-2.pdf

Table 2. Malpractice claims per 100,000 population for different specialties. ${ }^{\star}$

\begin{tabular}{lllllllll}
\hline Year & Psych. & Anesth. & Surg. & Ped. & Psych. Rate & Anesth. Rate & Surg. Rate & Ped. Rate \\
\hline 2004 & 38 & 341 & 3412 & 1556 & 0.012967 & 0.11636 & 1.16432 & 0.53098 \\
2005 & 40 & 402 & 3328 & 1728 & 0.013525 & 0.13592 & 1.12526 & 0.58427 \\
2006 & 54 & 290 & 2893 & 1534 & 0.018085 & 0.09712 & 0.96888 & 0.51374 \\
2007 & 65 & 264 & 2737 & 1373 & 0.021553 & 0.08754 & 0.90755 & 0.45527 \\
2008 & 20 & 235 & 2673 & 1332 & 0.006571 & 0.07721 & 0.87819 & 0.43762 \\
2009 & 29 & 268 & 2464 & 1275 & 0.009446 & 0.08729 & 0.80259 & 0.41530 \\
2010 & 35 & 245 & 2299 & 1251 & 0.011336 & 0.07935 & 0.74463 & 0.40519 \\
2011 & 19 & 244 & 2434 & 1086 & 0.006098 & 0.07831 & 0.78115 & 0.34853 \\
\hline
\end{tabular}

${ }^{\star}$ Includes multiple observations from the same practitioner.

Psych.=psychiatry, Anesth.=anesthesiology, Surg.=surgery, Ped.=pediatrics.

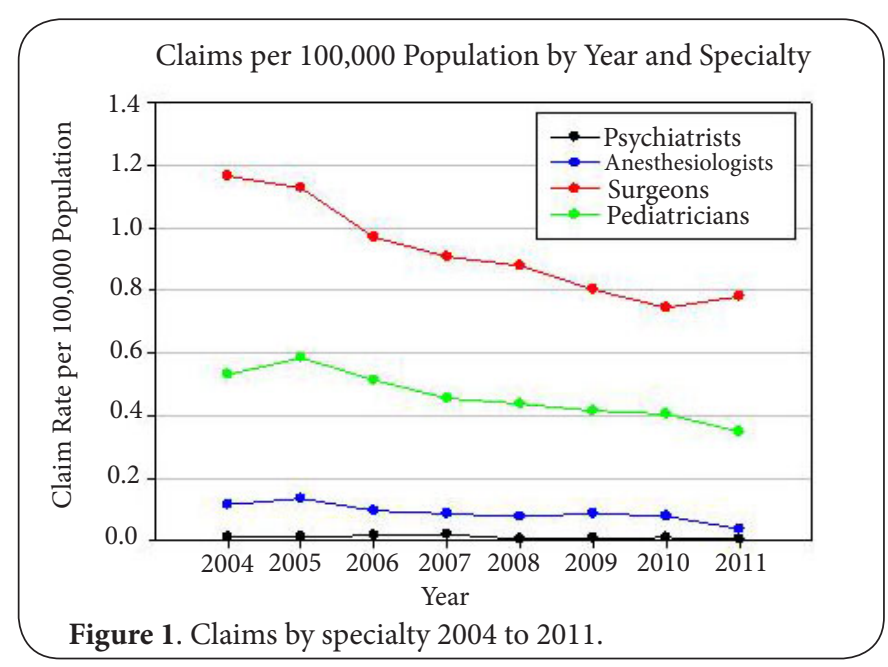

ulation. Using this metric, all specialties showed a decline over the study period. This decline was significant for pediatricians $(p<0.0001)$ and surgeons $(p<0.0001)$. Although the data does not allow us to compare the specialties on a per physician basis, we can examine differences in trends of the different specialties over the study period. The trend of lower rates of malpractice claims for surgeons was significantly better than all other specialties $(p<0.0001$ in each case). The trends toward improvement in malpractice claims for pediatrics were significantly different from both anesthesia $(p<0.001)$ and psychiatry $(\mathrm{p}<0.0001)$.

Table 3 and Figure 2 give the findings for total mean payment per incident (including multiple incidents by the same professional). All the specialties show a decrease in mean payment over time when adjusted for 2004 dollars, although psychiatry shows more variability. The only specialty where the trend of the decline is significant is pediatrics $(p<0.001)$. Comparisons of trend lines among the different specialties does not in general show much difference, although there is a trend for a difference between pediatrics and surgery $(p<0.02)$ perhaps because at the end of the time period pediatrics is rising a bit and surgery is declining a bit.
Table 3. Mean total payment by year and specialty adjusted to 2004 dollars*.

\begin{tabular}{lllll}
\hline Year & Psych & Anesth & Surg & Ped \\
\hline 2004 & $\$ 182,704$ & $\$ 372,723$ & $\$ 257,812$ & $\$ 444,951$ \\
2005 & $\$ 260,003$ & $\$ 328,902$ & $\$ 248,446$ & $\$ 458,351$ \\
2006 & $\$ 176,709$ & $\$ 314,545$ & $\$ 246,225$ & $\$ 458,635$ \\
2007 & $\$ 169,386$ & $\$ 357,207$ & $\$ 265,055$ & $\$ 445,071$ \\
2008 & $\$ 364,327$ & $\$ 338,323$ & $\$ 248,961$ & $\$ 428,129$ \\
2009 & $\$ 306,946$ & $\$ 302,709$ & $\$ 254,285$ & $\$ 397,269$ \\
2010 & $\$ 154,744$ & $\$ 308,956$ & $\$ 249,682$ & $\$ 392,406$ \\
2011 & $\$ 154,697$ & $\$ 304,228$ & $\$ 238,193$ & $\$ 414,304$ \\
\hline
\end{tabular}

${ }^{*}$ Includes multiple observations from the same practitioner. Psych=psychiatry, Anesth=anesthesiology, Surg=surgery, Ped-pediatrics.

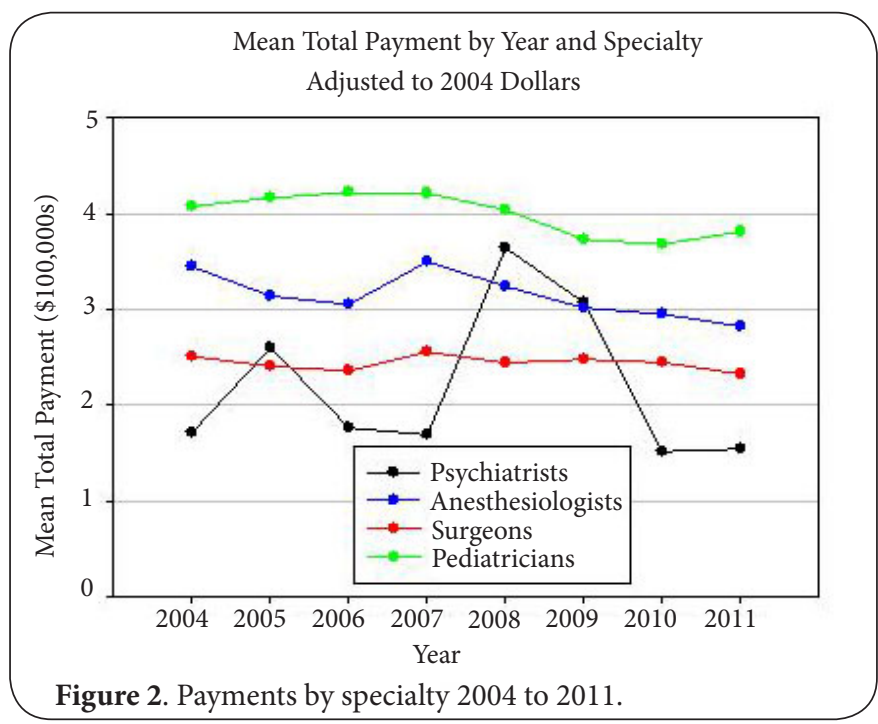

\section{Discussion}

\section{Systemic factors}

The literature indicates that physicians in the United States 
are suffering from some system-generated challenges. The largest of these appears to be the "fault" system. Most would agree it seems fair that those patients suffering a severe unexpected medical injury should receive some kind of compensation. Medical professionals would also agree that at times unexpected medical injury occurs in spite of physicians following reasonable medical practice. In a "no fault" system compensation, the case of standard medical practice combined with an unexpected adverse outcome is not a problem. In our current "fault" system, a physician must be found to blame or the patient cannot collect. Thus, even though there are times the physician has erred, physicians in the "fault" system become a target despite the presence or absence of an error. An error and a physician or hospital to blame must be found for payment to be made.

There are models used in other countries that do not require the doctor to be at fault. Barbot et al., [24] discuss the French dual track system. On one track there is an administrative system to collect damages that does not require finding the doctor at fault. The key issue here is the level of damage to the patient. A second track provides a separate system for complaints against doctors, which does not result in com-pensation to the patient but does bring the doctor's actions under professional scrutiny.

Bismark et al., [25] examined a New Zealand system similar to that of France. Here the ratio of compensation requests (without regard to fault of the doctor) to non-compensation requests (alleging fault in care but would not receive compensation for this) was 3.3 to 1 , even though both requests could be pursued at the same time. The major variable predicting a compensation request was financial need (injury during prime working years or severe nonfatal injuries). Bismark et al., [26] notes that even though there are few institutional barriers in New Zealand, relatively few claims are filed.

Erichsen [27] reported on the Danish no fault system. The interesting finding here is that the number of claims and costs increased over time and the number of claims was higher after the initiation of a no fault system. Erichsen interprets this to mean that as the prior fault system did not adequately redress injuries. However, this also could have been due to the increase in claims where there was a bad outcome but fault could not be placed on the doctor.

Wallis et al., [16] examined the claims pattern pre and post starting the no fault system in New Zealand. Claims for compensation increased but complaints against doctors decreased. They felt this led to less accountability, but it also may be that bad outcomes not due to physician error no longer need to be pursued as physician error.

The fault system does not serve either the doctor or patient well. For the doctor there is a great deal of stress over a considerable period of time and the process is quite time consuming. For the patient there is a complicated, prolonged and stressful process until financial recompense is received. In addition, from a system point of view, expensive defensive medicine may be practiced. Although it could be argued that going to a no fault system might at times be "letting the doctor off the hook" for less than optimal performance, there is no reason why a system to monitor and enforce quality of physician treatment could not be set up independent of a system for compensation of an injured patient.

There are other important systemic factors. Financial pressures on organizations, doctor groups or individual practices can result in doctors seeing more patients with less time per patient. This could theoretically increase the possibility of clinical error. The presence of physician help programs or physician wellness programs could be a modifying factor in improving physician function. State laws on the length of statute of limitations and damage caps can also significantly affect the rates of malpractice.

\section{Individual factors}

Individual factors in malpractice seem to involve either errors of commission or errors of omission. Errors of commission occur when an action is decided upon, performed, and does not go well. In medicine (in this case), the problem is evident to all involved and the parties concerned are fairly easy to identify. The best example of this is surgery, which may explain why the surgical specialties are often considered at high risk for malpractice. This focus on the problem and the participants is somewhat independent of whether the decision to operate was correct and whether the procedures used were appropriate and technically well performed. Errors of omission are actions that are not taken and are therefore less visible, although not necessarily less damaging. From the review of the literature, it appears that failure to make a diagnosis or incorrect diagnosis fits this category in malpractice. It is more difficult to fault someone for not making a diagnosis or a correct diagnosis, but the literature indicates this failure is an important driver of malpractice claims.

\section{Data analysis findings}

The nature of the National Practitioner Data Base precludes direct comparison of frequency of malpractice events between specialties but does allow the trends over time for these specialties to be compared. All specialties showed a decline in frequency in malpractice claims, but the trend of the change is different between different specialties. Similarly, there is a reduction in mean malpractice payment for all specialties, but it does not follow the same trend in all specialties. This would indicate that rates of improvement differ between specialties in these variables. (The amount of payment might be considered a rough proxy for severity of the malpractice). There have been previous reports on medical specialty malpractice using the NPDB. There is a report on anest-hesiologists examining the frequency of malpractice claims and the amount of paid for these claims for the years 1991 to 2004 [22]. They concluded that over that period the number of anesthesiology malpractice payments decreased while the average 
Reich et al. Journal of Public Health Aspects 2015,

amount of each payment increased. A report on pediatricians examined data from February 2004 to December 2005 [7] and concluded that there were fewer malpractice cases in adults than children but that the amount paid in each malpractice suit in children was higher. Neither of these reports conflict with the current findings.

Chandra et al., [6] examined malpractice rates and payments for the period from 1991 to 2003. Although the number of payments remained the same during this period, the amount of payment increased $52 \%$. The rate of this growth had moderated toward the end of the period with the 2000 to 2003 rate of growth being only $6 \%$. This finding is complementary to our findings, which begin in 2004 and which show that the decline in growth actually became a decline as time went on.

A change in the rate of malpractice can have many possible causes both systemic and individual. It is not clear which are driving the decrease in rates we found. Overall, we have found that malpractice rates are variable over time and between specialties. Some of this is systemic and would need to be addressed by policy makers. On the individual level, we seem to be dealing with errors of commission (such as surgery) where there happens to be a bad outcome and errors of omission (such as failure to make a diagnosis or failing to make the correct diagnosis). The different specialties appear to have different issues that may require different approaches to risk management.

\section{Limitations}

There are limitations to the methods used. One limitation is the nature of the NPDB, which was not designed to be a research tool. The specialties we identified must be considered best estimates from the variables and data available in the NPDB and not precise identification of these specialties. The NPDB does not contain the information necessary to compare specific specialties directly, which is why we compared trends among specialties rather than doing a direct comparison. There is some evidence that some variables may not always be reliably reported. Levine et al., [28] found that a relatively small proportion of doctors disciplined by medical societies or hospitals and which are reported to the NPDB are reported to state medical boards. This is why we did not examine those variables in this report. In addition, there may be discipline by a medical board, which does not involve a malpractice claim. That was not addressed in this paper. Another limitation was that this report did not discuss the literature on the effect of training of American medical graduate physicians versus foreign medical graduate physicians.

We know that all malpractice claims examined were by physicians because the data was coded by presence or absence of an MD degree. We also know the type of incident that occurred (e.g., mental health, pediatrics, etc.). However, a limitation is that we do not know that all MDs sued for a specific type of incident were specializing in that area. For example, a general practitioner could conceivably be involved in a behavioral health malpractice claim. This represents another limitation of the data.

Some studies performed outside of the United States were examined for the sake of a complete review. It should be noted that these international studies may or may not be applicable to malpractice in the United States.

\section{Conclusions}

There are both systemic and individual sources of risk for malpractice claims. Systemic risks include working in a system where the physician must be found at fault for the patient to receive compensation; physicians who are subject to financial pressures; the availability of physician health programs; the presence of monitoring of malpractice issues; and the legal environment, including the length of statute of limitations and caps on compensation from malpractice suits. Individual risk factors include practicing medicine in a "high risk" specialty and diagnostic errors. NPDB data analysis indicates a decline in the frequency of malpractice claims and amounts paid for each claim for the medical specialties of anesthesia, surgery, pediatrics and psychiatry over the years from 2004 to 2011.

\section{Competing interests}

The authors declare that they have no competing interests.

\section{Authors' contributions}

\begin{tabular}{|l|c|c|}
\hline Authors' contributions & JR & AS \\
\hline Research concept and design & $\checkmark$ & $\checkmark$ \\
\hline Collection and/or assembly of data & $\checkmark$ & -- \\
\hline Data analysis and interpretation & $\checkmark$ & $\checkmark$ \\
\hline Writing the article & $\checkmark$ & $\checkmark$ \\
\hline Critical revision of the article & $\checkmark$ & $\checkmark$ \\
\hline Final approval of article & $\checkmark$ & $\checkmark$ \\
\hline Statistical analysis & $\checkmark$ & -- \\
\hline
\end{tabular}

\section{Acknowledgement}

We would like to acknowledge the help of our proof reader Rebecca J. Wyse.

\section{Publication history}

Editor: Nicola Shaw, Algoma University, Canada. Received: 31-Dec-2014 Final Revised: 02-Apr-2015 Accepted: 10-Apr-2015 Published: 18-Apr-2015

\section{References}

1. Mello MM, Chandra A, Gawande AA and Studdert DM. National costs of the medical liability system. Health Aff (Millwood). 2010; 29:1569-77. I Article | PubMed Abstract | PubMed Full Text

2. Peleg $D$ and Orvieto R. [Physicians' psychological reactions to malpractice litigation]. Harefuah. 1997; 133:635-6. | PubMed

3. Seabury SA, Chandra A, Lakdawalla DN and Jena AB. On average, physicians spend nearly 11 percent of their 40-year careers with an open, unresolved malpractice claim. Health Aff (Millwood). 2013; 32:111-9. | Article | PubMed

4. Amaral-Garcia $S$ and Grembi V. Curb your premium: the impact of monitoring malpractice claims. Health Policy. 2014; 114:139-46. | Article I PubMed

5. Brooks E, Gendel MH, Gundersen DC, Early SR, Schirrmacher R, Lembitz $\mathrm{A}$ and Shore JH. Physician health programmes and malpractice claims: 
Reich et al. Journal of Public Health Aspects 2015,

reducing risk through monitoring. Occup Med (Lond). 2013; 63:274-80. Article | PubMed

6. Chandra A, Nundy S and Seabury SA. The growth of physician medical malpractice payments: evidence from the National Practitioner Data Bank. Health Aff (Millwood). 2005; Suppl Web Exclusives:W5240-W5-249. | Article | PubMed

7. Zuckerman S, Bovbjerg RR and Sloan F. Effects of tort reforms and other factors on medical malpractice insurance premiums. Inquiry. 1990; 27:167-82. | Article | PubMed

8. Danzon PM. The frequency and severity of medical malpractice claims: new evidence. Law Contemp Probl. 1986; 49:57-84. | Article | PubMed

9. Victoroff MS,Drury BM,Campagna EJ and Morrato EH. Impact of electronic health records on malpractice claims in a sample of physician offices in Colorado: a retrospective cohort study. J Gen Intern Med. 2013; 28:637-44. | Article | PubMed Abstract | PubMed Full Text

10. Ragan MR and George DV. United States Dental Education Debt and the Impact on Dental Ethics and Practice Liability. Journal of Forensic Odontostomatology. 2013; 31: 24. | Pdf

11. Lee CS, Nagy PG, Weaver SJ and Newman-Toker DE. Cognitive and system factors contributing to diagnostic errors in radiology. AJR Am J Roentgenol. 2013; 201:611-7. | Article | PubMed

12. Jena $A B$, Seabury $S$, Lakdawalla $D$ and Chandra $A$. Malpractice risk according to physician specialty. N Engl J Med. 2011; 365:629-36. Article | PubMed Abstract | PubMed Full Text

13. Carroll AE and Buddenbaum JL. High and low-risk specialties experience with the U.S. medical malpractice system. BMC Health Serv Res. 2013; 13:465. | Article | PubMed Abstract | PubMed Full Text

14. Bishop TF, Ryan AM and Casalino LP. Paid malpractice claims for adverse events in inpatient and outpatient settings. JAMA. 2011; 305:2427-31. | Article I PubMed

15. Saber Tehrani AS, Lee H, Mathews SC, Shore A, Makary MA, Pronovost PJ and Newman-Toker DE. 25-Year summary of US malpractice claims for diagnostic errors 1986-2010: an analysis from the National Practitioner Data Bank. BMJ Qual Saf. 2013; 22:672-80. | Article | PubMed

16. Wallis K. New Zealand's 2005 'no-fault' compensation reforms and medical professional accountability for harm. N Z Med J. 2013; 126:3344. | Article | PubMed

17. Sloan FA, Mergenhagen PM, Burfield WB, Bovbjerg RR and Hassan M. Medical malpractice experience of physicians. Predictable or haphazard? JAMA. 1989; 262:3291-7. | Article | PubMed

18. Entman SS, Glass CA, Hickson GB, Githens PB, Whetten-Goldstein $K$ and Sloan FA. The relationship between malpractice claims history and subsequent obstetric care. JAMA. 1994; 272:1588-91. | Article | PubMed

19. Taragin MI, Martin K, Shapiro S, Trout R and Carson JL. Physician malpractice: does the past predict the future? J Gen Intern Med. 1995; 10:550-6. | Article | PubMed

20. National Practitioner Data Bank for Adverse Information on Physicians and other Health Care Practitioners: charge for self-queries. Health Resources and Services Administration, HHS. Final rule. Fed Regist. 1999; 64:9921-2. | PubMed

21. National Practitioner Data Bank (b), Healthcare Integrity and Protection Data Bank. National Practitioner Data Bank Public Use Data File. | Pdf

22. Kain ZN. The National Practitioner Data Bank and anesthesia malpractice payments. Anesth Analg. 2006; 103:646-9. | Article | PubMed

23. Kain ZN and Caldwell-Andrews AA. What pediatricians should know about child-related malpractice payments in the United States. Pediatrics. 2006; 118:464-8. | Article | PubMed

24. Barbot J, Parizot I and Winance M. "No-fault" compensation for victims of medical injuries. Ten years of implementing the French model. Health Policy. 2014; 114:236-45. | Article | PubMed

25. Bismark M, Dauer E, Paterson R and Studdert D. Accountability sought by patients following adverse events from medical care: the New Zealand experience. CMAJ. 2006; 175:889-94. | Article | PubMed Abstract | PubMed Full Text

26. Bismark MM, Brennan TA, Davis PB and Studdert DM. Claiming behaviour in a no-fault system of medical injury: a descriptive analysis of claimants and non-claimants. Med J Aust. 2006; 185:203-7. | Article I PubMed

27. Erichsen M. The Danish patient insurance system. Med Law. 2001; 20:355-69. | Article | PubMed

28. Levine A, Oshel R and Wolfe S. State Medical Boards Fail to Discipline Doctors with Hospital Actions Against Them. Public Citizen. 2011. | Pdf

\section{Citation:}

Reich J and Schatzberg A. Empirical comparisons of malpractice claims of different medical specialties. J Public Health Aspects. 2015; 2:2. http://dx.doi.org/10.7243/2055-7205-2-2 